\title{
Increased Visfatin Expression Is Associated with Nuclear Factor-kB in Obese Ovalbumin-Sensitized Male Wistar Rat Tracheae
}

\author{
Mohammad Reza Aslania, c Rana Keyhanmanesh ${ }^{b}$ Mohammad Reza Alipour \\ a Ardabil Imam Khomeini Educational and Clinical Hospital, Ardabil University of Medical Sciences, Ardabil, \\ ${ }^{b}$ Drug Applied Research Center and 'Tuberculosis and Lung Diseases Research Center, Tabriz University of Medical \\ Sciences, Tabriz, Iran
}

\section{Significance of the Study}

- The present study showed that the expression levels of nuclear factor- $\kappa \mathrm{B}(\mathrm{NF}-\kappa \mathrm{B})$ and visfatin mRNAs in trachea tissue were markedly higher in diet-induced obesity ovalbumin (OVA)-sensitized rats compared with normal diet OVA-sensitized rats. Equally important, a significant positive correlation was observed between NF- $\kappa$ B mRNA expression and weight changes as well as visfatin mRNA. These findings indicate an alternative signaling pathway in the obesity associated with the OVA-sensitized animal model, and could be responsible for altered expression levels of adipokines and especially the role of visfatin and NF- $\mathrm{kB}$ in tracheal tissue.

\section{Keywords}

Obesity $\cdot$ Asthma $\cdot$ Nuclear factor-KB $\cdot$ Visfatin

\begin{abstract}
Objective: To investigate the effects of diet-induced obesity on the expression of nuclear factor- $\mathrm{KB}(\mathrm{NF}-\mathrm{kB})$ and visfatin messenger RNA in male Wistar rats' tracheae after sensitization with ovalbumin (OVA). Materials and Methods: Twenty male Wistar rats were divided into 4 groups ( $n=5$ for each group), which included a control group fed a normal diet (ND) and groups fed normal diet, OVA-sensitized (S+ND); high-fat diet (HFD) only (diet-induced obesity); and high-fat diet, OVA-sensitized (S+HFD). All animals were fed for 8 weeks with standard chow or a high-fat diet, and then were sensitized and challenged with OVA or saline for another 4 weeks as per the above groups. The rats were anesthetized, after which the necks were exposed and the tracheae iso-
\end{abstract}

\begin{tabular}{ll}
\hline KARGER & ( 2017 S. Karger AG, Basel \\
$\begin{array}{l}\text { E-Mail karger@karger.com } \\
\text { www.karger.com/mpp }\end{array}$ & $\begin{array}{l}\text { This is an Open Access article licensed under the terms of the } \\
\text { Creative Commons Attribution-NonCommercial 3.0 Un- } \\
\text { ported license (CC BY-NC) (www.karger.com/OA-license), } \\
\text { applicable to the online version of the article only. Distribu- } \\
\text { tion permitted for non-commercial purposes only. }\end{array}$
\end{tabular}

lated and examined for expression levels of NF-KB and visfatin mRNA with the real-time polymerase chain reaction method. Data were compared between the different groups using one-way analysis of variance. Results: The expression level of NF-KB mRNA in the S+HFD group was 2.67, which was statistically higher than the levels in the ND $(0.96 ; p=$ $0.001)$, S+ND (1.86; $p=0.05)$, and HFD (1.26; $p=0.001)$ groups. Also, the visfatin mRNA expression level in the S+HFD group was 4.21, which was higher than the levels in the ND (0.92), S+ND (1.79), and HFD (2.20) ( $p=0.001)$ groups. Conclusion: In this study, the expression levels of NF-KB and visfatin were markedly higher in the S+HFD group in comparison to the other groups. These findings indicate that alternative signaling pathways might be activated in diet-induced obesity associated with the OVA-sensitized animal model and could be responsible for possible altered sensitization phenotype.

(c) 2017 S. Karger AG, Basel

Mohammad Reza Alipour, PhD

Tuberculosis and Lung Diseases Research Center

Tabriz University of Medical Sciences

Tabriz (Iran)

E-Mail alipourmr52@gmail.com or alipourmr@tbzmed.ac.ir 


\section{Introduction}

The prevalence of asthma and obesity has been rising in recent years and numerous clinical studies have indicated a significant association between obesity and asthma [1]. Importantly, in the overweight and obese individuals, studies have shown a decreased response to inhaled corticosteroids [2] or long-acting $\beta$-agonists [3], which are the medications commonly used for treating asthma. The underlying mechanism(s) for this link is unclear, although a number of studies had explored some hypotheses, including inflammation, mechanical factors, and common genetic determinants $[1,4]$.

Transcription factor nuclear factor $-\kappa \mathrm{B}(\mathrm{NF}-\kappa \mathrm{B})$ involved in the pathophysiology of asthma is considered a master regulator of inflammatory and immune responses $[5,6]$. In various studies, NF- $\kappa B$ has been shown to play a critical role in maintaining the chronic inflammatory response in asthma $[5,7]$. NF- $\kappa B$ increases in the majority of chronic inflammatory conditions such as asthma and arthritis [7]. However, it has been reported that the effect of obesity on lung tissue involved inflammatory changes in pulmonary microenvironment [4]. Many interactions between the immune system and metabolism appear to be mediated by a complex network of soluble mediators secreted from immune cells and adipocytes, known as adipokines (also called adipocytokines) [8]. In this regard, it has been reported that adipokines increased airway allergic inflammation and could lead to airway hyperresponsiveness $[9,10]$, the main characteristics of bronchial asthma. There is much evidence supporting the important role of leptin and adiponectin in inflammatory processes in asthma, but only a little has been identified about other adipokines such as visfatin [10]. Visfatin, also known as pre-B cell colony-enhancing factor and nicotinamide phosphoribosyl transferase, was first discovered in lymphocytes, bone marrow, liver, muscle [11], and later in lungs [12]. The main sources of visfatin are granulocytes, monocytes, macrophages, and adipocytes [13]. A variety of human and animal studies have indicated that visfatin is a proinflammatory cytokine and is involved in regulating inflammation and innate immunity [14]. Hence, based on the above observations, it is proposed that in the obesity associated with asthma, altered expression levels of adipokines, with a special focus on the role of visfatin, as well as NF- $\kappa B$ mRNA and NF- $\kappa B$ protein levels could impact the asthma phenotype. Therefore, the objective of this study was to investigate the effects of a diet-induced obesity on levels of visfatin and NF- $\mathrm{kB}$ mRNA in the tracheae of male Wistar rats sensitized with ovalbumin (OVA).

\section{Materials and Methods}

\section{Animals and Diets}

Twenty male Wistar rats ( 8 weeks old, weighing approximately $160 \mathrm{~g}$ ) were obtained from Animal House, Tabriz University of Medical Science, Tabriz, Iran. All the rats were placed in cages ( $n=5$ per cage) under controlled conditions of $22^{\circ} \mathrm{C}$ and a $12-$ to 12-h light-dark cycle. Food and water were provided ad libitum throughout the acclimatization and experimental period.

After a week of acclimatization, all the rats were randomly divided into 4 groups ( $n=5$ in each group), which included a control group fed a normal diet (ND), an OVA-sensitized group with normal diet (S+ND), high-fat diet group (HFD diet-induced obesity), and an OVA-sensitized with high-fat diet group (S+HFD). The high-fat diet was to induce obesity as previously described [15]. Briefly, the high-fat diet was fat: $42 \%$ energy; protein: 19\%; and carbohydrate: $39 \%$ given to HFD and S+HFD while ND and S+ND rats were fed standard rat chow (fat: $11 \%$; protein: $28 \%$; and carbohydrate: 61\%) (Behparvar Feed Manufacturing Co., Iran).

After 8 weeks, sensitization of animals with OVA in the S+ND and $\mathrm{S}+\mathrm{HFD}$ groups was performed with the previous protocol [16] and lasted 4 weeks.

\section{Animal Sensitization}

Briefly, $1 \mathrm{mg}$ OVA and $200 \mathrm{mg}$ aluminum hydroxide (Sigma) were injected intraperitoneally on days 1 and 8 . From day 14, the animals were placed in a closed chamber (dimensions: $30 \times 20 \times$ $20 \mathrm{~cm}$ ) exposed to aerosol particles of 4\% OVA for 17-19 days, 15 min daily, using a nebulizer (CX3, Omron Health Care Europe B.V., the Netherlands). The rats of the ND and HFD groups were treated similarly with saline instead of OVA solution. Rats are easily sensitized using OVA and show immediate and late sensitization responses after an allergen challenge [17]. The study was approved by the Ethical Committee of Tabriz University of Medical Sciences.

\section{Body Weight}

The animals were weighed weekly at approximately 16:00 during the experiment. All rats were anesthetized and weighed, and the distance between rats' nose and anus (nasoanal length) was measured. Final body weight, Lee index, and percentage of body fat (BF\%) were also determined to calculate the obesity indexes used in rodents [18]. Briefly, the following formulae were used to calculate all obesity indexes [18]:

1. Percentage of body weight changes $(\%)=(($ Final weight initial weight)/initial weight) $\times 100$

2. Lee index $(\mathrm{mg} / \mathrm{mm})=$ Final weight ${ }^{0.33} /$ naso-anal length .

3. Percentage of body fat $(\%)=0.69$ (Lee index -274.8$)$.

\section{Tissue Preparation}

The rats were anesthetized with an intraperitoneal injection of ketamine (50 $\mathrm{mg} / \mathrm{kg}$ ) and xylazine $(5 \mathrm{mg} / \mathrm{kg})$; the chests and necks were opened and approximately $2 \mathrm{~cm}$ of the trachea was isolated. The trachea was divided into several 5-mm segments (5-6 ring cartilage) that were immediately placed between 2 horizontal hooks of stainless steel suspended in a $20-\mathrm{mL}$ organ bath (Schuler Organ Bath Type 809; March-Hugstetten, Germany) containing Krebs-Henseleit solution. The initial tension was $1 \mathrm{~g}$ throughout the experiment and the equilibrium period was $60 \mathrm{~min}$ in which, the bath solution was replaced every $15 \mathrm{~min}$. Contractility respons- 
Table 1. Weight changes and obesity indexes in the experimental groups

\begin{tabular}{|c|c|c|c|c|}
\hline Variables & ND & $\mathrm{S}+\mathrm{ND}$ & HFD & $\mathrm{S}+\mathrm{HFD}$ \\
\hline Initial body weight, $g$ & $162 \pm 3.50$ & $160.00 \pm 3.31$ & $161.00 \pm 3.31$ & $162.80 \pm 6.30$ \\
\hline Final body weight, $g$ & $327.20 \pm 13.84$ & $323.40 \pm 13.81$ & $373.60 \pm 6.58^{* * *,+++}$ & $378.60 \pm 16.14^{* * *,+++}$ \\
\hline Percentage of body weight change, $\%$ & $101.71 \pm 7.39$ & $102.07 \pm 5.29$ & $132.15 \pm 7.05^{* * *,+++}$ & $132.60 \pm 6.63^{* * *,+++}$ \\
\hline Lee index, $\mathrm{mg} / \mathrm{mm}$ & $307.02 \pm 3.35$ & $306.37 \pm 2.60$ & $317.55 \pm 2.7911^{* * *,+++}$ & $318.34 \pm 2.31^{* * *,+++}$ \\
\hline Percentage of body fat, $\%$ & $22.64 \pm 2.27$ & $21.77 \pm 1.79$ & $29.49 \pm 1.54^{* * *,+++}$ & $30.04 \pm 1.59^{* * *,+++}$ \\
\hline
\end{tabular}

ND, control with normal diet; S+ND, ovalbumin-sensitized with normal diet; HFD, high-fat diet alone; S+HFD, ovalbumin-sensitized with high-fat diet. Differences between results of ND with those of other groups: ${ }^{* * *} p<0.001$. Differences between results of the S+ND group with those of the HFD and S+HFD groups: ${ }^{+++} p<0.001$. For each group, $n=5$.

es were measured using vernier control type $850 \mathrm{~N}$ sensor (sensitivity range: $0-20 \mathrm{~g}$ and resolution: $0.2 \mathrm{~mm} /$ turn [Hugo-Sachs Elektronik, Germany]) and amplified with an amplifier (ML/118 quad bridge amp, March- Hugstetten, Germany) and recorded on power lab (ML-750,4channel recorder, March-Hugstetten, Germany).

\section{Assessment of Tracheal Response to Methacholine}

The contractility response to $1 \mathrm{mM}$ methacholine hydrochloride (Sigma Chemical Ltd., UK) as the magnitude of contraction was measured. At the end of the experiments, the tissue was weighed and then the contraction force was induced by methacholine (at plateau level) was calculated to express as $\mathrm{g}$ force/mg tissue weight ( $\mathrm{gF} / \mathrm{TW}$ ) for comparing the spasmogenic activity of these spasmogens between groups.

\section{Biochemical Measurements}

After the rats were anesthetized with ketamine and xylazine, blood samples (3-5 $\mathrm{mL}$ per rat) were withdrawn from the heart of fasted rats into EDTA tubes. Plasma total cholesterol (TC), triglycerides (TG), and high-density lipoprotein-cholesterol (HDL-C) concentrations were measured using an automatic blood analyzer (Bayer Corp., USA). TGs, TC, and HDL-C kits were obtained from Pars Azmoon Co., Iran. Low-density lipoprotein-cholesterol (LDL-C) was evaluated using the Friedewald formula: LDL-C = TC - (HDL-C + TG/5) [19].

\section{Tissue Sampling and Protein Measurement}

After withdrawing blood samples, the rats were sacrificed. Then tracheal tissues were removed and, after quick freezing with nitrogen, all tissues were stored at $-70^{\circ} \mathrm{C}$ temperature until NF- $\kappa \mathrm{B}$ measurement.

Tissue samples were weighed, the cellular contents were extracted with the homogenitor (Potter S, Germany) in PBS ( $\mathrm{pH} 7.2$ 7.4), and were centrifuged for $20 \mathrm{~min}$ at the speed of 3,000 rpm at $4{ }^{\circ} \mathrm{C}$. Then supernatants were removed and NF- $\kappa B$ molecules (antigens) were detected by the ELISA method. The ELISA assays were performed using commercial ELISA kits (Hangzhou Eastbiopharm Co., Ltd., catalog: BYEK 1184). The absorption was determined with the microplate absorbance reader at $450 \mathrm{~nm}$. The lower detection limit was $2 \mathrm{pg} / \mathrm{mL}$ for visfatin (coefficients of variation; intra-assay: $10 \%$, inter-assay: $12 \%$ ).

Tracheal NF- $\kappa \mathrm{B}$ and Visfatin in Obese-Asthmatic Male Wistar Rats

\section{Real-Time Polymerase Chain Reaction}

The RNA content and purity were measured using a Nanodrop 1000 spectrophotometer (Thermo Scientific, Wilmington, DE, USA). For determination of NF- $\kappa$ B and visfatin mRNA expression levels, the Revert Aid First-Strand cDNA Synthesis Kit (Fermentas $\mathrm{GmbH}$, Leon-Rot, Germany) with the aid of random hexamer primers and MMLV reverse transcriptase (as a complete system for efficient synthesis of first-strand cDNA from mRNA or total RNA templates) was used.

With SYBR Green Master Mix (Exiqon), each cDNA was used as a template for separate assays for mRNA quantitative real-time PCR. The locked nucleic acid forward and reverse primer sets (Exiqon) for mRNA include: NF- $\kappa B 1$ (sense: $5^{\prime}$-AATTGCCCCGGCAT- $3^{\prime}$ and antisense: $3^{\prime}$-TCCCGTAACCGCGTA-5' [XM_342346.4]), visfatin (sense:5'-CCTCTTGAATTGCTCCTTCA-3' and antisense: ${ }^{\prime}$ '-CCGTATGGAGAAGATCATGG-3' [NM_177928]), and $\beta$-glucuronidase (sense:5'-GGCTCGGGGCAAATT- ${ }^{\prime}$ and antisense: $3^{\prime}$-GGGGCAGCACGAT- ${ }^{\prime}$ [NM_017015.2]). Real-time PCR reactions were performed on a Rotor-Gene 6000 instrument (Corbett Life Science, Australia).

The PCR products were normalized with $\beta$-glucuronidase genes for mRNA samples. The $2^{-(\Delta \Delta \mathrm{Ct})}$ method was used to determine relative quantitative levels of NF- $\kappa \mathrm{B}$ and visfatin mRNA. Results were expressed as fold change versus the relevant controls [20].

\section{Statistical Analysis}

All results were given in means \pm SD. Data were compared between different groups using one-way analysis of variance with a Tukey-Kramer post hoc test. $p$ values $<0.05$ were considered significant. The correlation between NF- $\kappa \mathrm{B}$ and visfatin mRNA levels and weight was assessed with the Pearson correlation coefficient. SPSS 16 software was used for statistical analysis.

\section{Results}

The body weight characteristics of the rats are given in Table 1. The final body weight in HFD (373.60 g) and S+HFD (378.60 g) animals were significantly higher than $\mathrm{ND}(327.20 \mathrm{~g})$ and S+ND (323.40 g) animals $(p<0.001)$. 


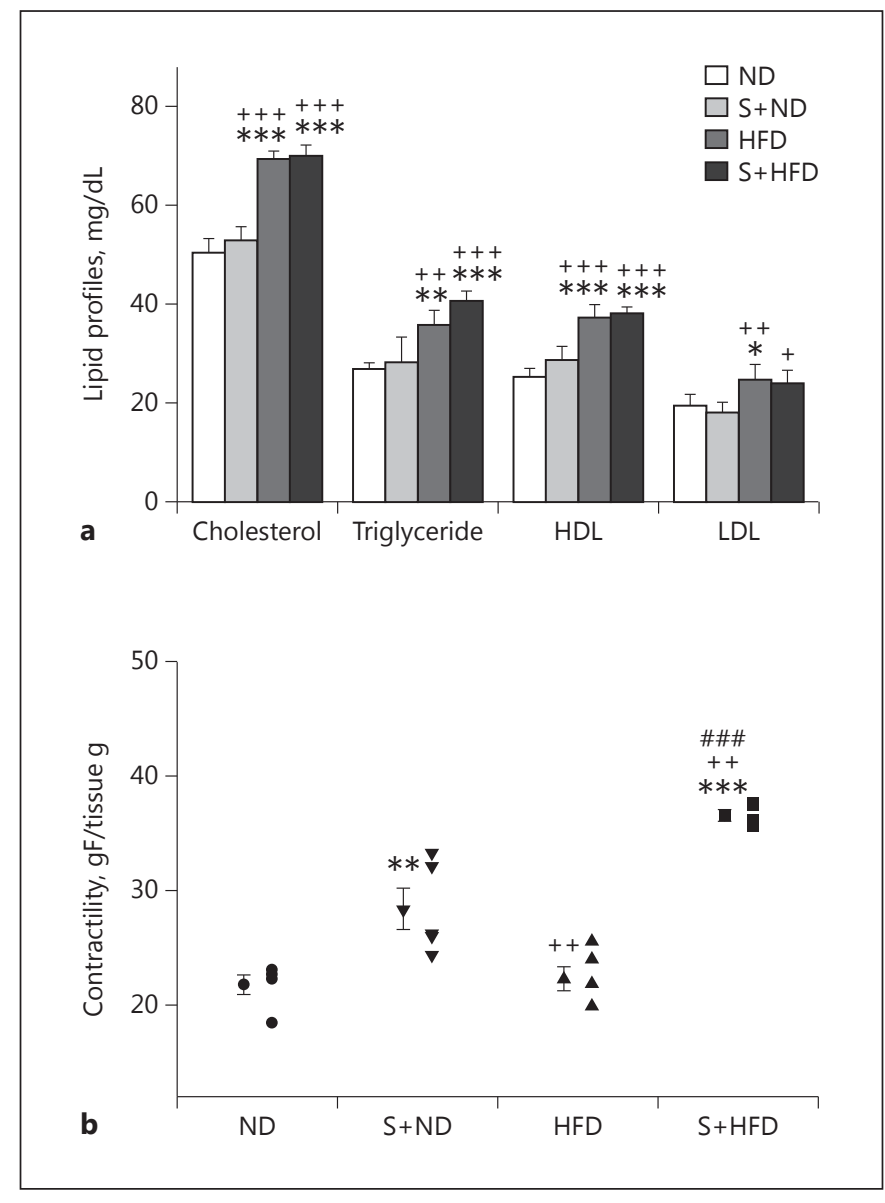

Fig. 1. a Serum levels of total cholesterol, triglyceride, high-density lipoprotein (HDL), and low-density lipoprotein (LDL) in experimental groups. Values are depicted as means \pm SD. b Individual values and means \pm SD of tracheal contractility to methacholine (g force $[\mathrm{gF}] /$ tissue $\mathrm{g}$ ) (contractility response to $1 \mathrm{mM}$ methacholine) in experimental groups. ND, control with normal diet; S+ND, ovalbumin-sensitized with normal diet; HFD, high-fat diet group; S+HFD, ovalbumin-sensitized with high-fat diet. Statistical differences between the ND and other groups: ${ }^{*} p<0.05$; ** $p<0.01$; *** $p<0.001$. Statistical differences between the sensitized normal diet and obese groups: ${ }^{+} p<0.05 ;{ }^{++} p<0.01$; ${ }^{+++} p<0.001$. Statistical difference between the HFD and S+HFD groups: ${ }^{\# \#} p<0.001$. For each group, $n=5$.

Also, the Lee index in HFD (317.55) and S+HFD (318.34) groups were enhanced when compared with the ND (307.02) and S+ND (306.37) groups $(p<0.001)$. Moreover, results showed that BF\% in the HFD (29.49\%) and S+HFD (30.04\%) groups was significantly higher than the ND $(22.64 \%)$ and S+ND $(21.77 \%)$ groups $(p<0.001)$. However, there were no significant differences in final body weight, Lee index, and BF\% between the ND and $\mathrm{S}+\mathrm{ND}$ groups, or HFD and S+HFD groups.
The lipid profiles of TC, TG, HDL-C, and LDL-C in the diet-induced obesity groups (HFD and S+HFD) are shown in Figure 1a and they were significantly higher than the non-diet-induced obesity groups $(p<0.05$ to $p<$ 0.001 ). There were no significant differences in the lipid profile test among the normal diet control groups (ND vs. $\mathrm{S}+\mathrm{ND}$ ) and the diet-induced obesity groups (HFD vs. S+HFD).

Pearson correlation analyses of lipid profile and NF$\kappa \mathrm{B}$, visfatin mRNA, and NF- $\kappa \mathrm{B}$ protein are shown in Table 2. There were significant positive correlations between NF- $\kappa \mathrm{B}$ mRNA with TC $(r=0.466)$, HDL $(r=$ $0.442)$, and TG $(r=0.597)$. Also, there was borderline correlation $(r=0.388)$ between visfatin mRNA and LDL, and significant correlations with other lipid profiles.

\section{Trachea Response to Methacholine}

The contractility results obtained from $\mathrm{gF} / \mathrm{TW}$ shows that $\mathrm{gF} / \mathrm{TW}$ in S+HFD $(36.60 \pm 0.95)$ animals was significantly higher than other groups $(p<0.01$ to $p<0.001$, Fig. 1b). Also, gF/TW in S+ND $(28.43 \pm 4.01)$ animals was significantly higher than those in the ND and HFD groups $(p<0.01)$. There was no significant difference in $\mathrm{gF} / \mathrm{TW}$ between the ND and HFD animals.

\section{Visfatin mRNA Expression Level in Tracheal Tissue}

Visfatin mRNA expression in the ND group $(0.92 \pm$ $0.25)$ was significantly lower than the $\mathrm{S}+\mathrm{ND}(1.79 \pm 0.32$, $p<0.05)$, HFD $(2.22 \pm 0.6, p<0.01)$, and S+HFD (4.21 \pm $0.39, p<0.001)$ groups. Also, visfatin mRNA expression in the S+HFD group increased significantly compared with the HFD and S+ND groups $(p<0.001)$. Although mean visfatin mRNA expression was higher in the HFD group $(2.22 \pm 0.60)$ compared with the $\mathrm{S}+\mathrm{ND}$ group (1.79 $\pm 0.32)$, the difference was not statistically significant $(p=0.376)$ (Fig. 2a).

There was a significant positive correlation between visfatin mRNA expression and final body weight ( $r=$ $0.716)$, percentage of weight changes $(r=0.710)$, Lee in$\operatorname{dex}(r=0.708)$, and BF\% $(r=0.689)$ (Table 2$)$.

\section{NF- $\kappa B$ mRNA Expression Level in Tracheal Tissue}

The NF- $\kappa \mathrm{B}$ mRNA expression in rat tracheal tissue is presented in Figure 2b. The OVA sensitization in the $\mathrm{S}+\mathrm{ND}$ group caused a significant increase in NF- $\kappa \mathrm{B}$ mRNA expression $(1.86 \pm 0.20)$ when compared with the ND group $(0.96 \pm 0.13, p<0.01)$, and was borderline significantly higher than HFD $(1.26 \pm 0.22, p=0.09)$. On the other hand, after diet-induced obesity and OVA 
Table 2. Pearson correlation analysis of parameters of study with NF- $\kappa \beta$ mRNA, visfatin mRNA, and NF- $\kappa \beta$ protein levels in trachea tissue

\begin{tabular}{|c|c|c|c|c|c|c|}
\hline \multirow[t]{2}{*}{ Parameters } & \multicolumn{2}{|c|}{$N F-\kappa \beta$ mRNA } & \multicolumn{2}{|c|}{ Visfatin mRNA } & \multicolumn{2}{|c|}{$\mathrm{NF}-\kappa \beta$ protein } \\
\hline & $r$ & $p$ & $r$ & $p$ & $r$ & $p$ \\
\hline Cholesterol & 0.466 & 0.038 & 0.734 & 0.000 & 0.301 & 0.198 \\
\hline Triglyceride & 0.595 & 0.006 & 0.787 & 0.000 & 0.447 & 0.048 \\
\hline $\mathrm{HDL}$ & 0.442 & 0.051 & 0.776 & 0.000 & 0.301 & 0.198 \\
\hline LDL & 0.295 & 0.207 & 0.388 & 0.091 & 0.143 & 0.548 \\
\hline Final body weight & 0.395 & 0.085 & 0.716 & 0.000 & 0.306 & 0.190 \\
\hline Percentage of body weight change & 0.453 & 0.045 & 0.710 & 0.000 & 0.345 & 0.136 \\
\hline Lee index & 0.370 & 0.108 & 0.708 & 0.000 & 0.301 & 0.197 \\
\hline Percentage of body fat & 0.354 & 0.126 & 0.689 & 0.001 & 0.297 & 0.203 \\
\hline
\end{tabular}

HDL, high-density lipoprotein; LDL, low-density lipoprotein.

sensitization, the amount of NF- $\kappa \mathrm{B}$ mRNA expression levels were significantly higher in the S+HFD group $(2.63 \pm 0.67)$ than in the other groups, especially the $S+N D$ group $(1.86 \pm 0.20)(p<0.05$ to $p<0.001)$. There was no significant difference between the ND and HFD groups.

A significant positive correlation was found between NF- $\mathrm{BB}$ mRNA expression and percentage of weight changes ( $r=0.453, p<0.05$; Table 2$)$. This correlation was not significant with final body weight and other obesity indexes, Lee index, and BF\%. Further, there was a marked positive correlation between NF- $\kappa \mathrm{B}$ mRNA expression and visfatin mRNA expression level in tracheal tissue $(r=0.778, p<0.001$; Fig. $2 \mathrm{~d})$.

\section{NF- $\kappa B$ Protein in Tracheal Tissue}

The NF- $\kappa \mathrm{B}$ protein level in OVA-sensitized groups $(\mathrm{S}+\mathrm{ND}$ and $\mathrm{S}+\mathrm{HFD})$ was significantly higher compared to the control groups ( $p<0.05$ to $p<0.001$; Fig. $2 \mathrm{c}$ ). Although mean NF- $\mathrm{KB}$ protein was higher in the S+HFD group $(66.57 \pm 7.14)$ compared with the $\mathrm{S}+\mathrm{ND}$ group $(60.78 \pm 6.70)$, the difference was not significant $(p=$ $0.403)$. Also, there was no significant $(p=0.962)$ difference between ND and HFD.

There was no significant correlation between $N F-\kappa B$ protein and obesity indexes (percentage of weight changes, Lee index, BF\%, and final body weight) (Table 2). Additionally, there was a marked positive correlation between NF- $\kappa \mathrm{B}$ protein level and visfatin $\mathrm{mRNA}$ expression level in tracheal tissue ( $r=0.675, p<0.001$; Fig. $2 \mathrm{e})$.

\section{Discussion}

In this study, diet-induced obesity caused high body weight and obesity indices in rats (percentage of weight changes, Lee index, and fat percent) similar to the previous study [15]. Also, in diet-induced obesity, lipid profiles (total cholesterol, triglyceride, HDL-C and LDL-C) were significantly higher in obese groups than other groups.

Airway contractility to methacholine was higher in sensitized lean and diet-induced obesity rats compared with nonsensitized controls. The airway contractility to methacholine was highest in the diet-induced obesity sensitized rats. Airway hyperresponsiveness, bronchoalveolar lavage fluid eosinophilia, and smooth muscle hypertrophy are some characteristics of asthma. In our present study, OVA sensitization showed airway hyperresponsiveness in an animal model and confirmed previous reports of bronchial hyperreactivity development in obese rats [21].

The results of the present study showed that the expression level of visfatin significantly increased in obese OVA-sensitized rats. Fat tissue is considered as an endocrine organ which indicates increased inflammatory activity. Mouse models of obesity and asthma have illuminated the possible role of leptin, adiponectin, and other inflammatory mediators in the association between obesity and asthma [1]. Moreover, the results showed that there was a positive correlation between serum lipid profile and expression level of visfatin mRNA, and also between weight gain and visfatin expression in the trachea in the OVA-sensitization condition. Additionally, we found a marked positive correlation between visfatin 


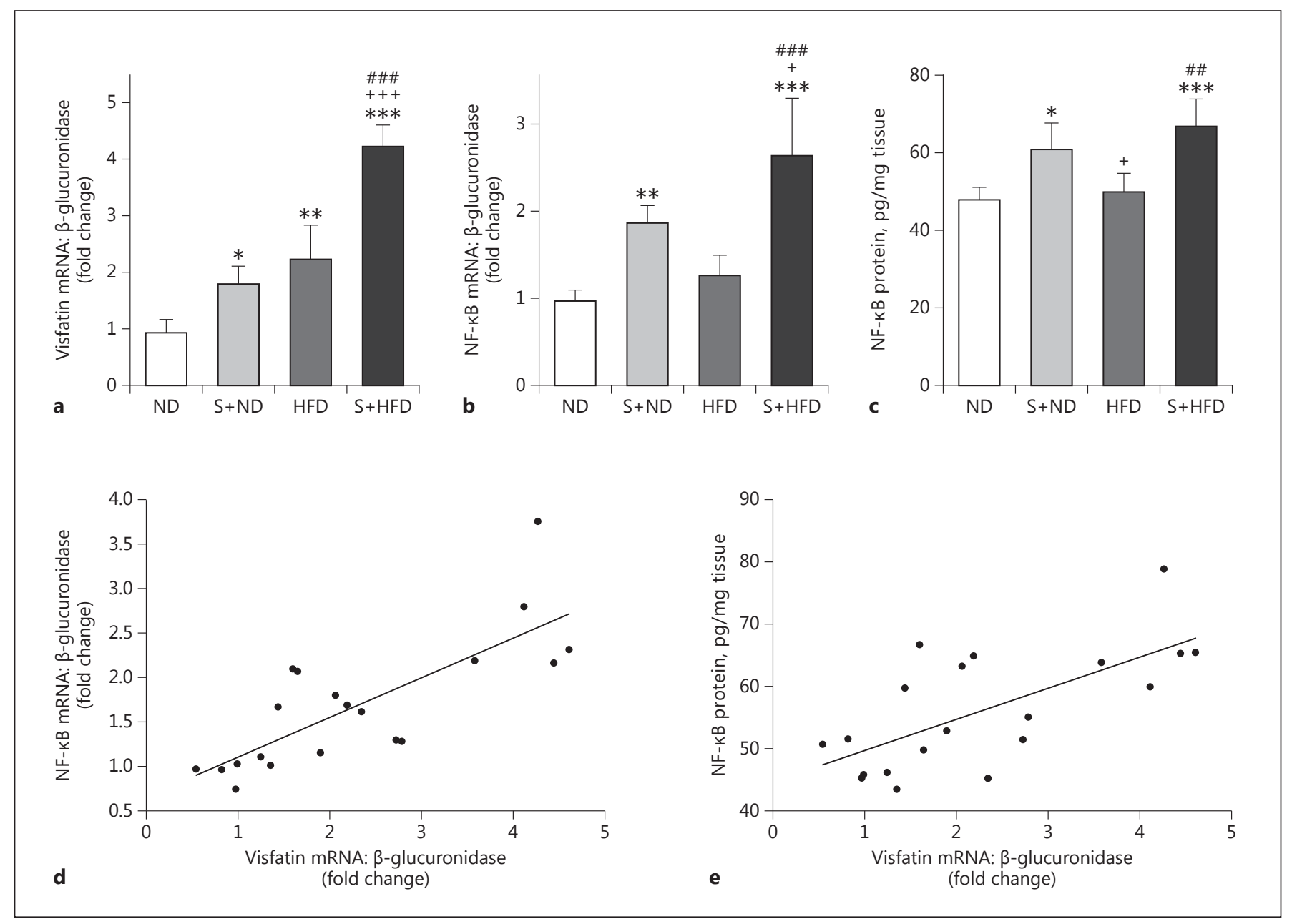

Fig. 2. Expression level of visfatin mRNA (a), expression level of $N F-\kappa B$ mRNA (b), and protein level of NF- $\kappa B(\mathbf{c})$ in the tracheal tissue of the experimental groups. $\mathbf{d}$ Pearson correlation analysis of visfatin mRNA and NF- $\mathrm{kB}$ mRNA in tracheal tissue. e Pearson correlation analysis of visfatin mRNA and NF- $\kappa B$ protein level in tracheal tissue. Values are depicted as means \pm SD. ND, control with normal diet; S+ND, ovalbumin-sensitized with normal diet;

mRNA expression and NF- $\kappa \mathrm{B}$ mRNA and protein levels in the trachea. It has been shown that the activity of proinflammatory functions wase exerted by visfatin [22]. Visfatin upregulates the production of IL- $1 \beta$, IL-6, IL-10, and TNF- $\alpha$ in human monocytes [22] in an extracellular cytokine manner through the NF- $\kappa B$ activation pathway. Furthermore, visfatin is able to inhibit apoptosis in neutrophils and lead to perpetuation of inflammation [23]. It is believed that visfatin acts as a potent chemotactic factor, especially for recruitment of monocytes [24]. Local inflammation in arthrosclerosis plaque has the main role in the pathogenesis of coronary arterial disease and sys-
HFD, high-fat diet; S+HFD, ovalbumin-sensitized with high-fat diet. Statistical differences between ND and other groups: ${ }^{*} p<$ $0.05 ;{ }^{* *} p<0.01 ;{ }^{* * *} p<0.001$. Statistical differences between S+ND and HFD groups: ${ }^{+} p<0.05 ;^{++} p<0.001$. Difference between HFD and S+HFD: ${ }^{\# \#} p<0.01$; ${ }^{\# \#} \mathrm{p}<0.001$. For each group, $n=5$.

temic inflammation is thought to interact with this process [25]. Perhaps a similar theory is also associated in the obese asthmatic conditions.

OVA sensitization in rats led to overexpression of NF$\kappa B$ mRNA in tracheal tissue. Surprisingly, after diet-induced obesity in the OVA-sensitized group, the NF- $\mathrm{BB}$ mRNA expression level was markedly higher compared to the lean OVA-sensitized group. Further results of this study showed that there was a positive correlation between the serum lipid profile and expression level of NF$\kappa \mathrm{B}$ mRNA, as well as between weight gain and NF- $\kappa \mathrm{B}$ expression in the trachea in the rat OVA-sensitization 
condition. The authors did not rule out the effect of lipid profile changes on cellular signal pathways. It has been shown that free fatty acids are able to activate inflammatory pathways in tissues [26]. Elevated NF- $\kappa B$ in this study model may be the result of an increased lipid profile, which need further study. Also, in an effort to further understand the role of NF- $\kappa \mathrm{B}$ in the relationship between obesity and asthma, the NF- $\kappa B$ protein level in the trachea was tested in this study. The results indicated that the protein level of NF- $\kappa \mathrm{B}$ increased in the OVA-sensitization state, with a greater increase in diet-induced obesity OVA-sensitized rats.

Obesity is a low-grade chronic proinflammatory state, identified by enhances in serum levels of various chemokines, cytokines, and soluble cytokine receptors, and results in airway inflammation and asthma severity [27]. Previous reports have indicated that NF- $\mathrm{kB}$ has an important role in allergic inflammation of airways [28]. A study conducted by Poynter et al. [5] showed that rapid and selective activation of NF- $\kappa B$ occurred in mice airway epithelium challenged and sensitized with antigen. Additionally, inhibition of NF- $\mathrm{KB}$ activity in these cells reduced the inflammatory response to antigen challenge [29]. In animal models of allergen-mediated airway inflammation and in patients with asthma, NF- $\mathrm{B}$ activity has been demonstrated in lung tissue, particularly in airway epithelial [30]. From the results of this study, it can be inferred that increased expression and protein levels of NF- $\mathrm{KB}$ in the trachea, as well as increased levels of circulating cytokines in this condition, can synergistically impact airway inflammation and may lead to deterioration of sensitization. But it should be kept in mind that measurement of $\mathrm{p} 65$ of NF- $\mathrm{kB}$ is a better way to show the activity of NF- $\kappa \mathrm{B}$ which needs to be further studies.

Increased expression level of visfatin $\mathrm{mRNA}$, as well as increased NF- $\kappa$ B expression in trachea tissue in the OVA- sensitization condition can, at least in part, indicate an altered signaling pathway in the obesity condition. Enhanced adipokines in the trachea may change the airway responsiveness in obese allergic airway inflammation. The findings of the current study, such as upregulation of visfatin and NF- $\kappa B$ in diet-induced obesity sensitized with OVA condition in animal model support the hypothesis that not only systemic but also local inflammation may be involved in pathophysiologic changes in obesity-associated allergic airway inflammation.

\section{Conclusion}

Diet-induced obesity caused a high expression of NF$\kappa \mathrm{B}$ and visfatin mRNA as well as NF- $\kappa \mathrm{B}$ protein levels in the tracheae of male OVA-sensitized rats. NF- $\kappa B$ has an important role in allergic airway inflammation. In obesity associated with the OVA-sensitization condition, elevated NF-kB mRNA and protein levels in trachea tissue indicate that cell-signaling pathways are increasing inflammatory status. There is also a significant correlation between visfatin and NF-kB in trachea tissue, suggesting a local inflammatory change in tissue, independent (or dependent) of possible systemic changes in obesity associated with OVA-sensitization conditions.

\section{Acknowledgment}

This study was funded by Tuberculosis and Lung Diseases Research Center of Tabriz University of Medical Sciences (92/4-6/9).

\section{Disclosure Statement}

The authors report no conflicts of interest.

\section{References}

1 Shore SA: Obesity and asthma: possible mechanisms. J Allergy Clin Immunol 2008;5: 1087-1093.

2 Forno E, Lescher R, Strunk R, et al: Decreased response to inhaled steroids in overweight and obese asthmatic children. J Allergy Clin Immunol 2011;3:741-749.

3 Boulet L-P, Franssen E: Influence of obesity on response to fluticasone with or without salmeterol in moderate asthma. Respir Med 2007;11:2240-2247.
4 Shore SA, Fredberg JJ: Obesity, smooth muscle, and airway hyperresponsiveness. J Allergy Clin Immunol 2005;5:925-927.

5 Poynter ME, Irvin CG, Janssen-Heininger YM: Rapid activation of nuclear factor $-\kappa B$ in airway epithelium in a murine model of allergic airway inflammation. Am J Pathol 2002;4: 1325-1334.

6 Bureau F, Bonizzi G, Kirschvink N, et al: Correlation between nuclear factor- $\kappa \mathrm{B}$ activity in bronchial brushing samples and lung dysfunction in an animal model of asthma. Am J Respir Crit Care Med 2000;4:1314-1321.
7 Rico-Rosillo G, Vega-Robledo GB: The involvement of NF- $\kappa \mathrm{B}$ transcription factor in asthma. Rev Alerg Mex 2011;58:107-111.

8 Mojiminiyi OA, Al Mulla F, Abdella NA Which obesity index best explains the link between adipokines, coronary heart disease risk and metabolic abnormalities in type 2 diabetes mellitus? Med Princ Pract 2009;2:123129
Tracheal NF- $\kappa \mathrm{B}$ and Visfatin in Obese-Asthmatic Male Wistar Rats
Med Princ Pract 2017;26:351-358 DOI: $10.1159 / 000475772$ 
9 Medoff BD, Okamoto Y, Leyton P, et al: Adiponectin deficiency increases allergic airway inflammation and pulmonary vascular remodeling. Am J Respir Cell Mol Biol 2009;4: 397-406.

10 Assad NA, Sood A: Leptin, adiponectin and pulmonary diseases. Biochimie 2012;10: 2180-2189.

11 Samal B, Sun Y, Stearns G, et al: Cloning and characterization of the cDNA encoding a novel human pre-B-cell colony-enhancing factor. Mol Cell Biol 1994;2:1431-1437.

12 Adeghate E: Visfatin: structure, function and relation to diabetes mellitus and other dysfunctions. Curr Med Chem 2008;18:18511862.

13 Friebe D, Neef M, Kratzsch J, et al: Leucocytes are a major source of circulating nicotinamide phosphoribosyltransferase (NAMPT)/pre-B cell colony $(\mathrm{PBEF}) /$ visfatin linking obesity and inflammation in humans. Diabetologia 2011;5:1200-1211.

14 Luk T, Malam Z, Marshall JC: Pre-B cell colony-enhancing factor (PBEF)/visfatin: a novel mediator of innate immunity. J Leukoc Biol 2008;4:804-816.

15 Buettner R, Schölmerich J, Bollheimer LC: High-fat diets: modeling the metabolic disorders of human obesity in rodents. Obesity 2007;4:798-808.
16 Aslani MR, Keyhanmanesh R, Khamaneh $A M$, et al: Lung altered expression of IL- $1 \beta$ mRNA and its signaling pathway molecules in obese-asthmatic male Wistar rats. Iran J Allergy Asthma Immunol 2016;15:183-197.

17 Zosky G, Sly P: Animal models of asthma. Clin Exp Allergy 2007;7:973-988.

18 Aslani MR, Keyhanmanesh R, Khamaneh AM, et al: Tracheal overexpression of IL- $1 \beta$, IRAK-1 and TRAF-6 mRNA in obese-asthmatic male Wistar rats. Iran J Basic Med Sci 2016;19:350-357.

19 Otunola GA, Oloyede OB, Oladiji AT, et al: Effects of diet-induced hypercholesterolemia on the lipid profile and some enzyme activities in female Wistar rats. Afr J Biochem Res 2010;6:149-154.

20 Schmittgen TD, Livak KJ: Analyzing realtime PCR data by the comparative CT method. Nat Protoc 2008;6:1101-1108.

21 Camargo CA, Weiss ST, Zhang S, et al: Prospective study of body mass index, weight change, and risk of adult-onset asthma in women. Arch Intern Med 1999;21:25822588.

22 Moschen AR, Kaser A, Enrich B, et al: Visfatin, an adipocytokine with proinflammatory and immunomodulating properties. J Immunol 2007;3:1748-1758.
23 Ye SQ, Simon BA, Maloney JP, et al: Pre-Bcell colony-enhancing factor as a potential novel biomarker in acute lung injury. Am J Respir Crit Care Med 2005;4:361-370.

24 Romano M, Sironi M, Toniatti C, et al: Role of IL-6 and its soluble receptor in induction of chemokines and leukocyte recruitment. Immunity 1997;3:315-325.

25 Ross R: The pathogenesis of atherosclerosis: a perspective for the 1990s. Nature 1993;362: 801-809.

26 Wesche H, Henzel WJ, Shillinglaw W, et al: MyD88: an adapter that recruits IRAK to the IL-1 receptor complex. Immunity 1997;6: 837-847.

27 Abdali D, Samson SE, Grover AK: How effective are antioxidant supplements in obesity and diabetes? Med Princ Pract 2015;3:201215.

28 Bannon A, Zhang S-D, Schock BC, et al: Cystic fibrosis from laboratory to bedside: the role of a 20 in NF- $\kappa B$-mediated inflammation. Med Princ Pract 2015;4:301-310.

29 Poynter ME, Cloots R, van Woerkom T, et al: NF- $\kappa B$ activation in airways modulates allergic inflammation but not hyperresponsiveness. J Immunol 2004;11:7003-7009.

30 Hamilton L, Davies D, Wilson S, et al: The bronchial epithelium in asthma - much more than a passive barrier. Monaldi Arch Chest Dis 2001;1:48-54. 